\title{
Mental Foramen Size, Position and Symmetry in a Multi-Ethnic, Urban Black Population: Radiographic Evidence
}

\author{
Seidu Adebayo Bello ${ }^{1,2}$, John Ademola Adeoye ${ }^{1}$, Nosa Ighile ${ }^{1}$, Nathan Ukuoghene Ikimi1 \\ ${ }^{1}$ Department of Dental and Maxillofacial Surgery, State House Medical Center, Aso-Rock, Asokoro, Abuja, Federal Capital \\ Territory, Nigeria. \\ ${ }^{2} \mathrm{QH}$ Specialist Dental Clinics and Research Center, Gwarinpa, Abuja, Federal Capital Territory, Nigeria.
}

\author{
Corresponding Author: \\ John Adeoye \\ State House Medical Centre (SHMC), Asokoro, Abuja \\ Nigeria \\ Phone: +2348082032391 \\ E-mail: adeoyejohnademola@gmail.com
}

\begin{abstract}
Objectives: To determine the approximate location, shape and dimensions of the mental foramen in African subjects using panoramic radiographs.

Material and Methods: This study analysed 320 orthopantomograms of subjects from two centres. The analysis was done using the radiographic software tools (SIDEXIS, Bensheim, Germany) which allowed for determination of the position, shape and dimensions of the foramen. Furthermore, the right and left mental foramina were compared to ascertain both shape and positional symmetry.

Results: Most of the foramina analysed were horizontally positioned between the mandibular first and second premolars $(65.9 \%)$ and vertically positioned greater than $2 \mathrm{~mm}$ below the apex of the second mandibular premolars. The average vertical dimension and horizontal dimension of the foramen is 2.87 (SD 1) $\mathrm{mm}$ and 3.56 (SD 1.23 ) $\mathrm{mm}$ respectively with $55.2 \%$ of the foramen analysed being ovoid in shape. Asymmetrical mental foramina were seen in 164 subjects (51.3\%) while 156 subjects had symmetrical mental foramina $(48.7 \%)$.

Conclusions: The mental foramen is most commonly located between the mandibular premolars, greater than $2 \mathrm{~mm}$ below the apex of the second mandibular premolars. They are usually ovoid in shape with an almost equal distribution of asymmetry and symmetry.
\end{abstract}

Keywords: bicuspids; mandible; computer-assisted radiographic image interpretation; urban population.

Accepted for publication: 29 November 2018

To cite this article:

Bello SA, Adeoye JA, Ighile N, Ikimi NU.

Mental Foramen Size, Position and Symmetry in a Multi-Ethnic, Urban Black Population: Radiographic Evidence

J Oral Maxillofac Res 2018;9(4):e2

URL: http://www.ejomr.org/JOMR/archives/2018/4/e2/v9n4e2.pdf

doi: $10.5037 /$ jomr.2018.9402 


\section{INTRODUCTION}

The mental nerve is a key factor in many of the surgical and clinical procedures in routine clinical practice [1]. This nerve together with its accompanying vessels passes through the mental foramen which is described as a funnel like opening on the anterolateral surface of the mandible at the terminus of the mental canal [2]. The inferior alveolar nerve and vessels after being conveyed through the mandibular canal exit the mental foramen as the mental nerve and vessels which innervates the lower lip, labial mucoperiosteum of the ipsilateral lower incisors, canine and premolars as well as the mentum [1-3].

The anatomic as well as radiographic size, position, shape and symmetry have been reported by several authors [4-6]. Philips et al. [4] reported that anatomically the mental foramen is generally oval shaped with an average size of $4.6 \mathrm{~mm}$ horizontally and $3.4 \mathrm{~mm}$ vertically, positioned at the apex of the mandibular second premolar in $62.7 \%$ of the population [4]. A similar study on sixty-six dry mandibles of Nigerians also reported the vertical position of the mental foramen to be in line with the long axis of the second premolar teeth, mostly round in shape and often symmetric [5]. The accurate identification of the mental foramen is important in both diagnostic and clinical procedures [4]. The position of the foramen is of significant importance in local anaesthesia of the terminal incisive branches of the inferior alveolar nerve together with the mental nerve. In clinical practice, anaesthesia of these nerves could be effectively obtained if the mental foramen is adequately located and the anaesthetic solution dropped within it [4]. In addition, the knowledge of the mental foramen position is important in endodontic procedures especially those involving the premolars, treatment of fractures related to the parasymphyseal region of the mandible [7], osteotomies required for orthognathic surgeries []], mandibular implant placement [ $\underline{8}]$ and construction of complete dentures in the mandible [7]. All these procedures require an accurate knowledge of the location and orientation of the mental foramen which cannot be clinically visualized or palpated [4], hence it is important to identify the foramen position and describe the appearance, radiographically. The mental foramen has also been misdiagnosed as periapical radiolucent lesion involving the mandibular premolars [4]. This fact further strengthened the need to determine its radiographic features. Several studies characterizing the position of mental foramen have been presented from different populations of the world, including
South-East Nigeria [5]. The aim of this study is to determine the position and characteristics of mental foramen from the multi-ethnic black subjects with a view to add to the body of evidence on the subject. The null hypothesis was that the mental foramen is ovoid in shape, equal in size, symmetrical and located between the mandibular premolars at a position inferior to the apices of their roots.

\section{MATERIAL AND METHODS Subjects and methods}

This is a retrospective clinical study, carried out at two centres: Dental and Maxillofacial Surgery Department of the State House Medical Centre (SHMC), as well as QH Specialist Dental Clinics and Research Centre, both located in Abuja, Nigeria. The study involved the analyses of orthopantomograms (OPGs) that were taken over a period of five years, from March 2013 to August 2018. Two observers (JA and AA) were calibrated and examined the digital forms of the panoramic radiographs in each center for a 2 week period difference. The selections were made on the premise that they satisfied the inclusion criteria.

\section{Inclusion criteria}

- Nigerian origin, age from 18 to 64 years.

- Film should show no radiographic exposure and processing artefacts.

- OPG of adult patient of both sexes with permanent dentition with no significant deformity or pathology of the mandible and had full complement of teeth anterior to the first molars.

- Radiographs having bilaterally visible mental foramina taken by the same machine.

\section{Exclusion criteria}

- Lack of clarity of OPG.

- Absence of one or both mental foramen, presence of benign pathologies, malignant pathologies or mandibular fractures.

The radiographs were obtained with the ORTHOPHOS XGPlusDS/Ceph (Sirona Dental systems $\mathrm{GmbH}$, Bensheim, Germany) digital panoramic machine (tube voltage: $60-90 \mathrm{kV}$, tube current: $3-16 \mathrm{~mA}$, total filtration of X-ray tube assembly: $>2.5 \mathrm{~mm}$ and magnification coefficient: 1.25). Data was collected and entered into a proforma for the study which had parameters for determining the horizontal and vertical position, shape, size and symmetry of the right and left mental foramen. 
The mental foramina were located in each OPG and measurements of both vertical and horizontal dimensions were made using the radiograph software (SIDEXIS, Bensheim, Germany) hand tool and measuring tools. The radiographic horizontal position of the mental foramen was divided into three parts using the modified Bokhari criteria [9]. These included:

- Position I: mesial to the first premolar.

- Position II: between the first and second premolars.

- Position III: distal to the second premolars.

The radiographic vertical position was divided into six types using the modified Ngeow and Yuzawati criteria [2]:

- Position 1: $>2 \mathrm{~mm}$ inferior to the apex of the first premolar.

- Position 2: $>2 \mathrm{~mm}$ inferior to the apex of the second premolar.

- Position 3: $<2 \mathrm{~mm}$ inferior or at the apex of the first premolar.

- Position 4: $<2 \mathrm{~mm}$ inferior or at the apex of the second premolar.

- Position 5: superior to the apex of the first premolar.

- Position 6: superior to the apex of the second premolar.

The shape of the foramen was estimated using the elliptical tool of the radiographic software. Symmetry was determined based on two criteria that included having the same shape as well as the same horizontal and vertical position on both sides.

Table 1. Comparison of the distribution of horizontal [9] and vertical [2] position of the mental foramina between the right and left sides among 320 subjects

\begin{tabular}{c|c|c|c}
\hline \multirow{2}{*}{} & Right & Left & \multirow{2}{*}{ P-value } \\
\cline { 2 - 3 } & N (\%) & N (\%) & \\
\hline \multicolumn{3}{|c}{ Horizontal position } \\
\hline I & $1(0.3)$ & $2(0.6)$ & \multirow{2}{*}{$0.001^{\mathrm{b}}$} \\
\hline II & $194(60.6)$ & $228(71.3)$ & \\
\hline III & $125(39.1)$ & $90(28.1)$ & \\
\hline \multicolumn{3}{|c}{ Vertical position } & \multicolumn{1}{|}{} \\
\hline 1 & $3(0.9)$ & $0(0)$ & \multirow{2}{*}{$0.981^{\mathrm{a}}$} \\
\hline 2 & $208(65)$ & $189(59.1)$ & \\
\hline 3 & $0(0)$ & $5(1.6)$ & \\
\hline 4 & $107(33.4)$ & $125(39.1)$ & \multicolumn{1}{|}{} \\
\hline 6 & $2(0.6)$ & $1(0.3)$ & \\
\hline
\end{tabular}

${ }^{a}$ No statistically significant association at the level $\mathrm{P}<0.05$, Chisquare test.

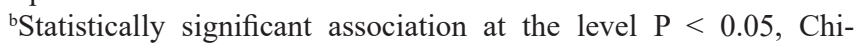
square test.

$\mathrm{N}=$ number of mental foramen observed at each horizontal position.

\section{Statistical analysis}

Data collected were analysed using Statistical Package for the Social Sciences (SPSS) version 20 (SPSS Inc., Chicago, USA). Frequency distributions and cross-tabulations were obtained, and Chi-square test was used to perform analyses of the mental foramina's vertical and horizontal position, shape and symmetry according to patients' age and sex. The ages of subjects were divided into two broad categories - young adult group (18 - 39 years) and middle-age group (40 - 64 years). Parametric data for the vertical and horizontal foramen dimensions were expressed as mean and standard deviation (M [SD]). The independent Students' t-test was used to compare the mean vertical and horizontal dimensions between the age groups and sex distribution. Statistical significance level was defined at $\mathrm{P}=0.05$.

\section{RESULTS}

A total of 1837 OPGs were extracted from both centres and after the inclusion and exclusion criteria were used, 320 OPGs were finally obtained as the definitive sample which was later analyzed. The Kappa $(\kappa)$ values for intra-observer agreement were 0.86 (AA) and 0.82 (AA) for the OPGs analyzed. This encompassing study assessed the radiographic position, size, shape and symmetry of the mental foramina from subjects within the age range 18 to 64 years (38.5 [SD 11.7] years, $54.1 \%$ males and $45.9 \%$ females). In addition, 172 subjects were young adults (53.8\%) while 148 subjects were middle-aged adults (47.2\%). All parameters used for the mental foramen analysis in this study were applied to both right and left sides of all reviewed OPGs.

\section{Horizontal and vertical position}

The modal horizontal position of the mental foramen was between the long axes of the mandibular first and second premolars as observed in 422 mental foramina (65.9\%) with 215 mental foramina positioned distal to the mandibular second premolar (33.6\%) (Table 1). Furthermore, there was no difference in the frequency pattern based on the horizontal position of the foramina between the right and the left sides although a position distal to the mandibular second premolars was commoner on the right side (Table 1).

The modal vertical position of the mental foramen was greater than $2 \mathrm{~mm}$ inferior to the apex of the second mandibular premolar as observed in 397 mental foramina examined (62\%) (Table 1). In total, a vertical position located at the apex or inferior to 
the apices of the second premolar was recorded in 629 mental foramen analysed $(98.3 \%)$. There was no disparity in the frequency of the vertical position of the mental foramina between the two sides analysed. However, a vertical position inferior to the apex of the first mandibular premolar was observed only on the left side.

\section{Size and shape}

The vertical dimension of the mental foramina in this study ranged from 0.8 to $8.1 \mathrm{~mm}$ with an average dimension of 2.87 (1) $\mathrm{mm}$. The average horizontal dimension was $3.56(1.25) \mathrm{mm}$ with a range of 0.7 to $7.9 \mathrm{~mm}$. The foramen on the right had an average vertical and horizontal dimensions of 2.88 (1) $\mathrm{mm}$ and $3.60(1.25) \mathrm{mm}$ respectively while the average left vertical and horizontal dimensions were 2.73 (1) $\mathrm{mm}$ and $3.52(1.24) \mathrm{mm}$ respectively. Young adults had larger horizontal and vertical dimensions of the foramen when compared to middle aged adults and this was statistically significant $(\mathrm{P}=0.046, \mathrm{P}=0.049)$ (Table 2).

The most prevalent shape in these subjects was the ovoid shape as observed in 353 mental foramina $(55.2 \%)$ with the irregular shape

Table 2. Sex and age distribution of mental foramina size among 320 subjects

\begin{tabular}{|c|c|c|c|c|}
\hline & $\begin{array}{l}\text { Vertical } \\
\text { diameter }\end{array}$ & $\begin{array}{c}\text { Horizontal } \\
\text { diameter }\end{array}$ & \multirow[t]{2}{*}{ P-value } \\
\hline & & Mean (SD) & Mean (SD) & \\
\hline \multirow{2}{*}{ Sex } & Male & $2.95(1.038)$ & $3.65(1.264)$ & $0.213^{\mathrm{a}}$ \\
\hline & Female & $2.81(0.962)$ & $3.54(1.226)$ & $0.446^{\mathrm{a}}$ \\
\hline \multirow{2}{*}{$\begin{array}{l}\text { Age } \\
\text { group }\end{array}$} & Young adults & $2.98(1.065)$ & $3.72(1.31)$ & $0.046^{\mathrm{b}}$ \\
\hline & Middle-aged adults & $2.77(0.921)$ & $3.46(1.155)$ & $0.049^{b}$ \\
\hline
\end{tabular}

${ }^{a}$ No statistically significant difference at the level $\mathrm{P}<0.05$, independent sample t-test.

${ }^{\mathrm{b}}$ Statistically significant difference at the level $\mathrm{P}<0.05$, independent sample t-test.

$\mathrm{SD}=$ standard deviation and uniformly circular shape accounting for $32.8 \%$ and $12 \%$ respectively. Also, there was no difference in the occurrence of the mental foramen shape between the right and the left side of the subjects as well as between the male and female subjects| (Table 3). Comparing the two main age groups (young and middle-aged adults), there was no difference in the shape distribution across both age groups although the irregular shape was higher in individuals less than 40 years. Figure 1 - 3 shows variants of the mental foramen shape observed.

\section{Symmetry}

Asymmetrical mental foramina were seen in 164 OPGs $(51.3 \%$ ) while $48.8 \%$ of subjects (156 OPGs) had symmetrical mental foramina. Regarding the age groups, 95 OPGs of young adults had asymmetrical mental foramina $(55.2 \%)$ while 79 OPGs of middleaged individuals were symmetrical (53.4\%) $(\mathrm{P}=0.521)$. Analysis further revealed that males had more asymmetrical mental foramina (53.8\%) while females had more symmetrical mental foramen $(51.7 \%)(\mathrm{P}=0.215)$. Figure $1-4$ shows variants of the mental foramen based on symmetry.

\section{DISCUSSION}

The mental nerve is transmitted by the mental foramen which also serves as an opening for the flow of local anaesthetic solutions to the incisive nerve [1]. Adequate determination of the radiographic position and features of the foramen in particular is much needed in order to corroborate anatomic descriptions that were made in times past. The horizontal position of the mental foramina observed in this study is consistent with the reports of AlJuboori et al. [10] among Malaysian subjects, Bokhari et al. [9] among Saudi Arabian subjects, Al-Shayyab et al. [11], among Iraqi subjects and Olasoji et al. [12] in Northern Nigerian subjects. Our finding was

Table 3. Sex distribution of the mental foramen shape among 320 subjects

\begin{tabular}{l|c|c|c|c|c|c}
\hline \multirow{2}{*}{ Shape } & \multicolumn{3}{|c|}{ Male } & \multicolumn{3}{|c}{ Female } \\
\cline { 2 - 3 } & Right & Left & \multirow{2}{*}{ P-value } & Right & Left & \multirow{2}{*}{ P-value } \\
\cline { 2 - 3 } & N (\%) & N (\%) & & N (\%) & N (\%) & \\
\hline Uniformly circular & $20(11.6)$ & $26(15)$ & & $13(8.8)$ & $18(12.2)$ & \multirow{2}{*}{$0.177^{\text {a }}$} \\
\cline { 2 - 3 } \cline { 2 - 3 } Irregular & $54(31.2)$ & $65(37.6)$ & & $47(32)$ & $44(29.9)$ & \\
\hline Ovoid & $99(57.2)$ & $82(47.4)$ & & $87(59.2)$ & $85(57.9)$ & \\
\hline \multicolumn{1}{c|}{ Total } & $173(100)$ & \multicolumn{2}{|c|}{$173(100)$} & $147(100)$ & $147(100)$ \\
\hline
\end{tabular}

${ }^{a}$ No statistically significant association at the level $\mathrm{P}<0.05$, Chi-square test.

$\mathrm{N}=$ number of mental foramen observed. 


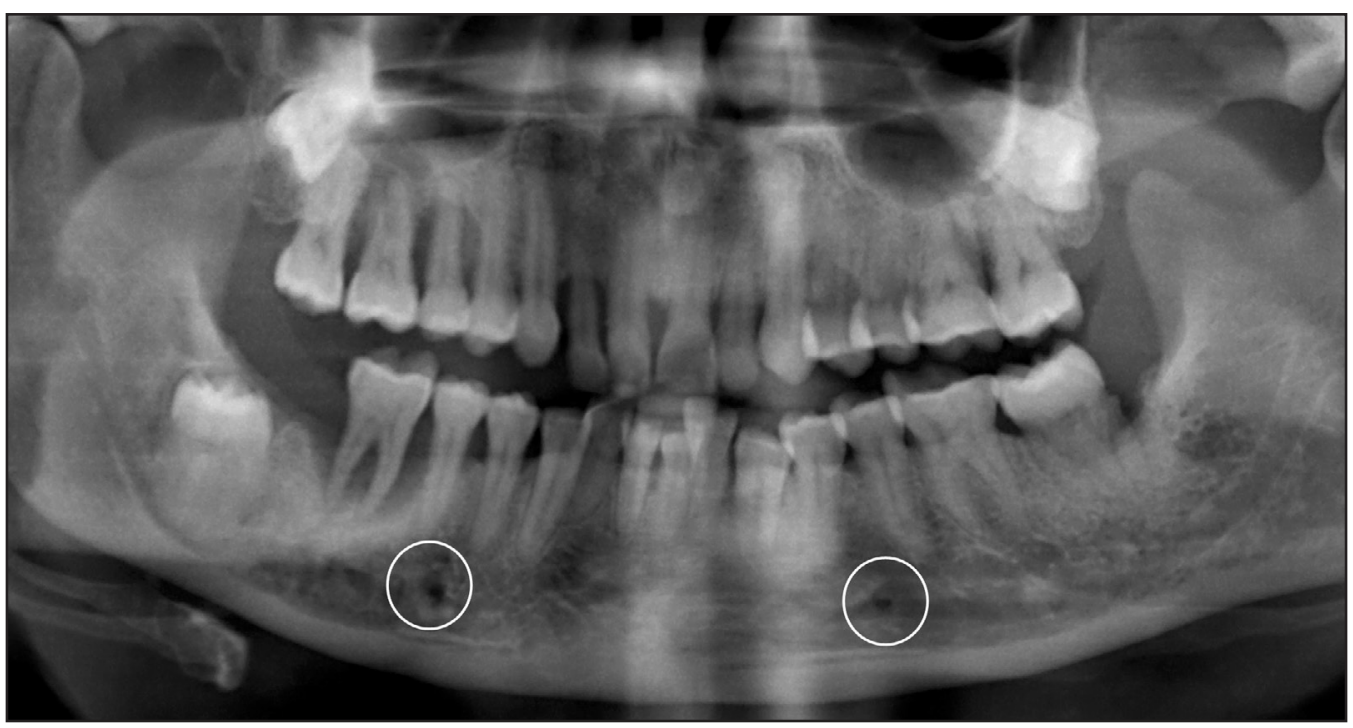

Figure 1. Panoramic radiograph showing irregularly shaped, symmetrical mental foramina.

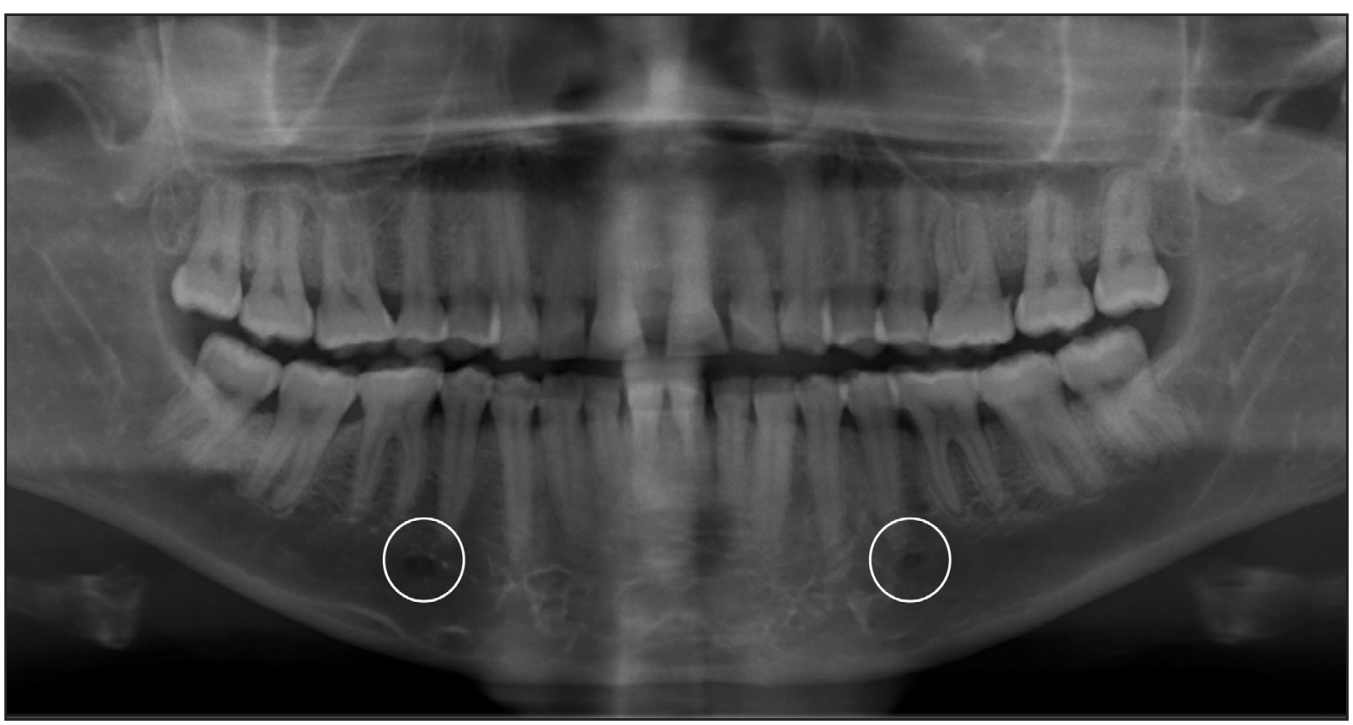

Figure 2. Panoramic radiograph showing ovoid shaped, asymmetrical mental foramina. The mental foramen were deemed asymmetrical due to the variations in the vertical position of the right and left foramen.

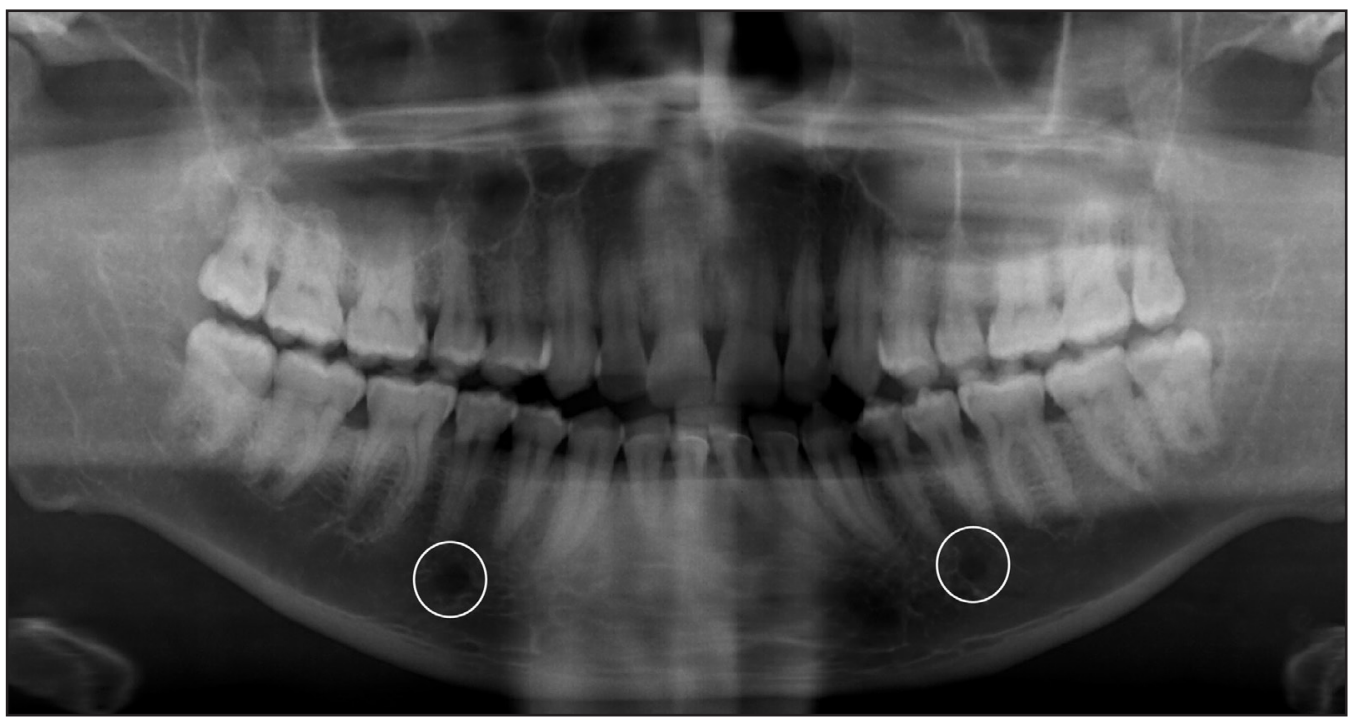

Figure 3. Panoramic radiograph showing uniformly circular, symmetrical mental foramina. 


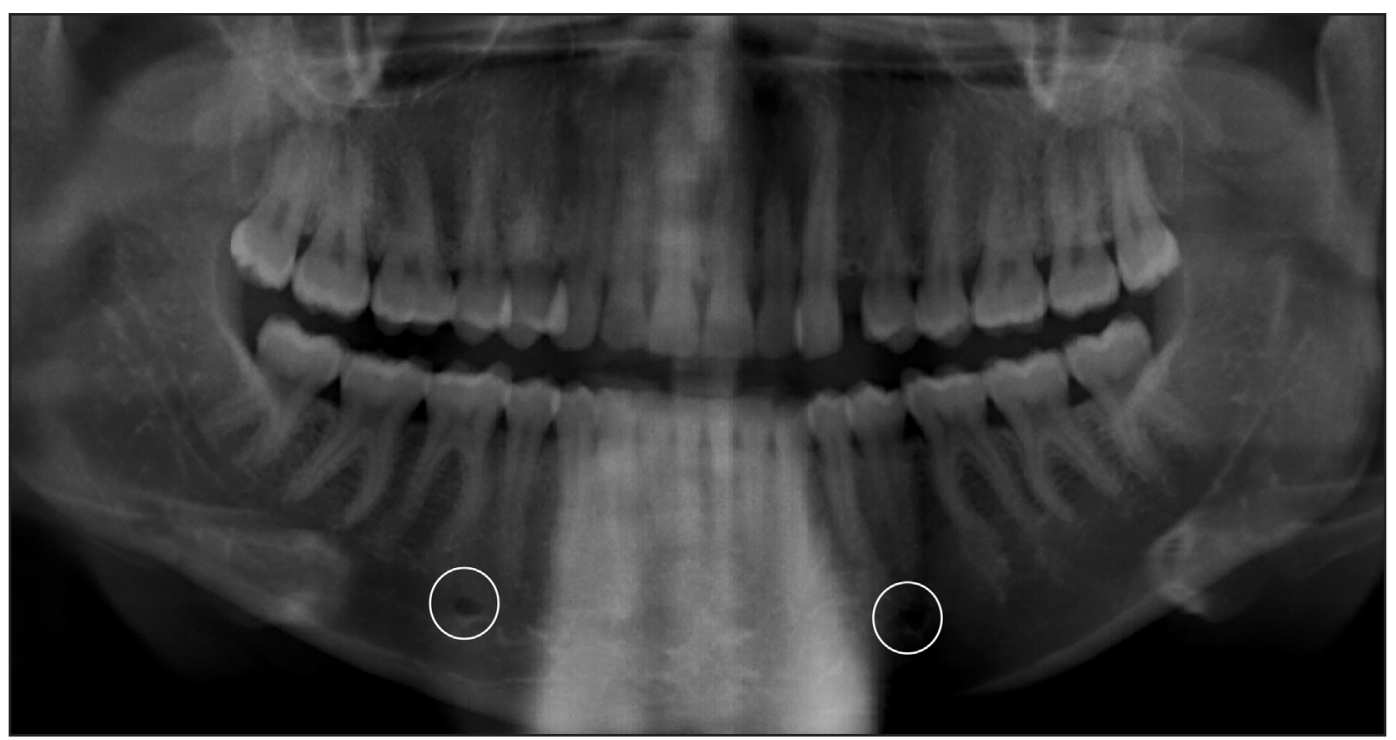

Figure 4. Panoramic radiograph showing asymmetric mental foramina based on position and shape variations. The right mental foramen has an ovoid shape and horizontally positioned distal to the long axis of 45 while the left mental foramen has an irregular shape and is horizontally positioned along the long axis of 35 .

however in contrast with the positional observations by Ukoha et al. [ $\underline{5}]$ in South-Eastern Nigeria with $58.3 \%$ of the foramen analysed horizontally positioned directly in line with the second mandibular premolar. Our findings further revealed that there was no difference in the occurrence of this horizontal position between the two sides in this study with rates of $60.6 \%$ and $71.3 \%$ obtained on the right and left foramina respectively. This is also similar to the report of Bokhari et al. [9] on 900 panoramic radiographs in Saudi Arabia where $72 \%$ of the left mental foramen and $52 \%$ of the right mental foramen were positioned between the mandibular premolars. Alok et al [13] however reported in their study in a Bareilly population of India, a horizontal position between the mandibular first and second premolars of $19.1 \%$ and $19.5 \%$ on the right and left sides which was lower and in contrast with our observations. The vertical position of the mental foramina analysed in this study is inconsistent with the observation of Bokhari et al. [9] in Saudi Arabia where majority of the mental foramina were positioned vertically inferior to the apex of the first mandibular premolar.

Regarding the size of the mental foramen, it was observed to be larger on the right than the left side. This finding was in contrast with the size variation reported by Phillips et al. [4] with 75 dry mandibles of American adults which the left mental foramen was observed to be larger. This may be as a result of the smaller sample size utilized in the later study. Our study observed a statistically significant difference in the size of the mental foramen based on the age group of the subjects with young adults having larger mental foramina than middle aged individuals indicative of narrowing of the foramen with increasing age, $\mathrm{P}=0.046$ and 0.049 consequently.

Most of the analysed mental foramina were ovoid in shape. Although this finding was also reported in some reports by Phillips et al. [4] in American subjects, Mbajiorgu et al. [14] in Zimbabwean subjects, Budhiraja et al. [15] in North Indian subjects and Oliveira et al. [16] in a South-American subjects, the second most common shape of the foramen was the round type which is not consistent with the shape distribution in our findings. This study observed a greater occurrence of irregularly shaped mental foramen than the uniformly circular/round shape. In contrast with the shape distribution in our study, AlShayyab et al. [11], al-Khateeb et al. [17] and Singh et al. [18] in their study among Jordanian, Indian and Iraqi subjects respectively, reported that most mental foramen were commonly observed as being round in shape than ovoid which is totally inconsistent with our reports. Ukoha et al. []ㅡ in a study involving 66 dry mandibles in South-Eastern Nigeria also reported the round type as the most common shape of the mental foramen which is contradicts our findings. This may be attributed to the higher number of the mental foramina analysed as well as the multi-ethnic location of our study. The contradictory report of different shapes of ovoid, round and irregular shapes among different ethnic groups of the world may also not be unconnected with the method of assessment which is subjective and difficult to standardize.

This study examined both shape and positional symmetry and observed that there was a fairly equal distribution with a slight majority of the mental foramina analysed being asymmetrical. 
This is in contrast to the reports of Alok et al. [13] in a Bareilly population in which the mental foramina were symmetrical in $81.7 \%$ of the subjects. Al-Shayyab et al. [11] in their Iraqi study involving 518 Iraqi panoramic radiographs also reported that $78.4 \%$ were symmetrical while $21.6 \%$ were asymmetrical. This is likely as a result of the limited criteria of determining symmetry based on the position that was used in their study. This study has reported more symmetrical foramina in middle aged patients compared with young adults. It could be concluded that symmetry is proportional with increasing age. This fact has not been a point of discussion in the literature and will require further studies for authentication. The difference in symmetry by studies could also be as a result of the dominant age in the different studies.

Some recent studies have also assessed the position and/or shape of the mental foramen using either three-dimensional cone-beam computed tomography (CBCT) techniques or intraoperatively in patients being managed on account of mandibular fractures. Alam et al. [19] in a retrospective study in Saudi Arabia involving CBCTs of 395 subjects reported a prevalent horizontal position that is in line with the long axis of the second premolar $(41.3 \%)$ and a vertical position inferior to its apex $(93.2 \%)$ with most of them being round in shape $(72.7 \%)$. While these results are consistent with our reports in terms of both horizontal and vertical position, the prevalent shape in our study is the ovoid shape which is in contrast with that observed by Alam et al. [18]. Also, $2.53 \%$ of subjects examined had one or two accessory mental foramen with the use of three-dimensional CBCT imaging while none were seen in all 320 OPGs analysed in this study which may indicate that this more recent imaging technique is more likely to reveal the presence of an accessory mental foramen than conventional radiographic techniques. In an intraoperative assessment of the position and shape of the mental foramen, El-Anwar et al. [20] observed in a study involving forty-six subjects with different types of mandibular fracture in Egypt that the mental foramen was horizontally positioned between the first and second premolars in $78.3 \%$ of subjects which is similar to our radiographic report.

\section{CONCLUSIONS}

It could be concluded that the landmark for the mental nerve block among Sub-Saharan Africans lies at a point about 2.5 to $3 \mathrm{~mm}$ apical to the mandibular premolar most commonly between the long axes of the mandibular first and second premolars. Mental foramina were found to be ovoid or sometimes irregular in shape and usually measures averagely $2.87 \mathrm{~mm}$ by $3.56 \mathrm{~mm}$. Younger individuals had larger mental foramina dimension than middle-aged adults with this finding being statistically significant. Also males had larger mental foramen than females although this was not statistically significant. Though symmetry and asymmetry of the mental foramina are fairly evenly distributed, no statistically significant difference was recorded. More symmetrical foramina were found in middle aged patients compared with young adults. It could be concluded that symmetry is directly proportional to the age. This fact has not been a point of discussion in the literature and will also require further studies for authentication.

\section{ACKNOWLEDGMENTS AND DISCLOSURE STATEMENTS}

The authors report no conflicts of interest related to this study. Also we would like to thank Drs Adebayo and Uduak $(\mathrm{QH}$ Specialists Dental Clinics and Research Center) for their help in data collection and radiograph analysis.

\section{REFERENCES}

1. Aher V, Pillai P, Ali MF, Mustafa M, Ahire M, Mudhol A, Kadri M. Anatomical Position of Mental foramen: a Review. Glob J Med Public Health. 2012 Jan-Fe;1(1):61-4. [URL: http://www.gjmedph.com]

2. Ngeow WC, Yuzawati Y. The location of the mental foramen in a selected Malay population. J Oral Sci. 2003 Sep;45(3): 171-5. [Medline: 14650583] [doi: 10.2334/josnusd.45.171]

3. Juodzbalys G, Wang HL, Sabalys G. Anatomy of Mandibular Vital Structures. Part II: Mandibular Incisive Canal, Mental Foramen and Associated Neurovascular Bundles in Relation with Dental Implantology. J Oral Maxillofac Res. 2010 Apr 1;1(1):e3. [Medline: 24421959] [PMC free article: 3886037] [doi: 10.5037/jomr.2010.1103]

4. Phillips JL, Weller RN, Kulild JC. The mental foramen: 1. Size, orientation, and positional relationship to the mandibular second premolar. J Endod. 1990 May;16(5):221-3. [Medline: 2074415] [doi: 10.1016/S0099-2399(06)81674-2]

5. Ukoha UU, KE Umeasalugo, UC Ofoego, OC Ejimofor, HC Nzeako, CG Edokwe. Position, shape and direction of the mental foramen in mandibles in South-Eastern Nigeria. Int J Biomed Res. 2013 Sep;4(9):499-503. [doi: 10.7439/ijbr.v4i9.349] 
6. Shah S, Vaze S, Kinhal K. A variation in the position of the mental foramen: a case report. J Maxillofac Oral Surg. 2010 Sep;9(3):307-9. [Medline: 22190812] [PMC free article: 3177449] [doi: 10.1007/s12663-010-0079-7]

7. Zivanović S. Some morphological characters of the East African mandible. Acta Anat (Basel). 1970;77(1):109-19. [Medline: 5504199] [doi: 10.1159/000143533]

8. Neiva RF, Gapski R, Wang HL. Morphometric analysis of implant-related anatomy in Caucasian skulls. J Periodontol. 2004 Aug;75(8):1061-7. [Medline: 15455732] [doi: 10.1902/jop.2004.75.8.1061]

9. Bokhari K, Shahrani AA, Mustafa AB, Hdban Y, Saleh M, Mofareh A. Position of Mental Foramen among Saudi Population: A Radiographic Study. Int J Experiment Dent Sci 2016 Jul-Dec;5(2):109-12. [URL: http://www.jaypeejournals.com]

10. Al-Juboori MJ, Al-Wakeel HA, Yun CM, Wen FS. Location of mental foramen among Malaysia populations: retrospective study by using orthopantomogram. World J Med Med Sci Res. 2013;1(5):85-90. [URL: http://wsrjournals.org/]

11. Al-Shayyab MH, Alsoleihat F, Dar-Odeh NS, Ryalat S, Baqain ZH. The mental foramen I: radiographic study of the anterior-posterior position and shape in Iraqi population. Int. J. Morphol. 2015 Mar;33(1):149-57. [doi: 10.4067/S0717-95022015000100024]

12. Olasoji HO, Tahir A, Ekanem AU, Abubakar AA. Radiographic and anatomic locations of mental foramen in northern Nigerian adults. Niger Postgrad Med J. 2004 Sep;11(3):230-3. [Medline: 15505658]

13. Alok A, Singh ID, Panat SR, Singh S, Kishore M, Jha A. Position and symmetry of mental foramen: A radiographic study in bareilly population. J Indian Acad Oral Med Radiol. 2017 Aug;29(1):16-9. [doi: 10.4103/jiaomr.JIAOMR_69_16]

14. Mbajiorgu EF, Mawera G, Asala SA, Zivanovic S. Position of the mental foramen in adult black Zimbabwean mandibles: a clinical anatomical study. Cent Afr J Med. 1998 Feb;44(2):24-30. [Medline: 9675967]

15. Budhiraja V, Rastogi R, Lalwani R, Goel P, Bose SC. Study of position, shape, and size of mental foramen utilizing various parameters in dry adult human mandibles from north India. ISRN Anat. 2012 Dec 17;2013:961429. [Medline: 25969824] [PMC free article: 4403559]

16. Oliveira JEM, Araújo ALD, Da Silva CMF, Sousa-Rodrigues CF, Lima FJC. Morphological and morphometric study of the mental foramen on the M-CP-18 Jiachenjiang point. Int J Morphol, 2009 Mar;27(1):231-38. [doi: 10.4067/S0717-95022009000100039]

17. al-Khateeb TL, Odukoya O, el-Hadidy MA. Panoramic radiographic study of mental foramen locations in Saudi Arabians. Afr Dent J. 1994;8:16-9. [Medline: 9590882]

18. Singh R, Srivastav AK. Study of position, shape, size and incidence of mental foramen and accessory mental foramen in Indian adult human skulls. Int J Morphol. 2010 Dec;28(4):1141-6. [doi: 10.4067/S0717-95022010000400025]

19. Alam MK, Alhabib S, Alzarea BK, Irshad M, Faruqi S, Sghaireen MG, Patil S, Basri R. 3D CBCT morphometric assessment of mental foramen in Arabic population and global comparison: imperative for invasive and non-invasive procedures in mandible. Acta Odontol Scand. 2018 Mar;76(2):98-104. [Medline: 29019277] [doi: 10.1080/00016357.2017.1387813]

20. El-Anwar MW, Sweed AH, Abdulmonaem G. Mental Foramen Relation to Mandibular Fracture. J Craniofac Surg. 2016 Nov;27(8):e743-e745. [Medline: 28005805] [doi: 10.1097/SCS.0000000000003078]

\section{To cite this article:}

Bello SA, Adeoye JA, Ighile N, Ikimi NU.

Mental Foramen Size, Position and Symmetry in a Multi-Ethnic, Urban Black Population: Radiographic Evidence

J Oral Maxillofac Res 2018;9(4):e2

URL: http://www.ejomr.org/JOMR/archives/2018/4/e2/v9n4e2.pdf

doi: $10.5037 /$ jomr.2018.9402

Copyright (C) Bello SA, Adeoye JA, Ighile N, Ikimi NU. Published in the JOURNAL OF ORAL \& MAXILLOFACIAL RESEARCH (http://www.ejomr.org), 30 December 2018.

This is an open-access article, first published in the JOURNAL OF ORAL \& MAXILLOFACIAL RESEARCH, distributed under the terms of the Creative Commons Attribution-Noncommercial-No Derivative Works 3.0 Unported License, which permits unrestricted non-commercial use, distribution, and reproduction in any medium, provided the original work and is properly cited. The copyright, license information and link to the original publication on (http://www.ejomr.org) must be included. 